\title{
Analysis of sorption of vehicle liquids with sand that appear after car accidents reproduced in laboratory scale
}

\author{
Andrzej Polanczyk ${ }^{1, *}$ Matgorzata Ciuka-Witrylak ${ }^{1}$, Oleksandr Synelnikov $^{2}$, Vasil Loik $^{2}$ \\ ${ }^{1}$ The Main School of Fire, Faculty of Fire Safety Engineering, 52/54 Slowackiego St., 01-629 \\ Warsaw, Poland \\ ${ }^{2}$ Lviv State University of Life Safety, Department of Fire Tactics and Rescue Works
}

\begin{abstract}
Introduction: Increasing number of vehicles corelates with an increase in car accidents' risk which pose a threat of environment contamination. Therefore, this study was undertaken to analyze the sorption process for two vehicle fluids contacted with sand. Methods and findings: Sorption process was analyzed with the use of dedicated experimental set-up in the laboratory scale. Contact of sand $\left(50 \mathrm{~cm}^{3}\right)$ with $100 \mathrm{~cm}^{3}$ of two sorbates (brake fluid-BF and diesel-D) with the following properties: pure $\mathrm{BF}$, pure $\mathrm{D}, 0.75-\mathrm{BF}$ and $0.25-\mathrm{D}, 0.5-\mathrm{BF}$ and $0.5-\mathrm{D}$, $0.25-\mathrm{BF}$ and $0.75-\mathrm{D}$ were investigated. Finally, non-linear regression for the mathematical description of sorption process was prepared. The results indicated that the higher amount of $\mathrm{D}$ in mixture the higher absorption of sorbate by sand. Moreover, the highest sorption was recorded for pure BF and the lowest for the mixture of equal amount of BF and D. Furthermore, analysis of absorbed mixtures volume indicated that for the composition of $0.25-\mathrm{BF}$ and $0.75-\mathrm{D}, 29 \mathrm{ml}$ of liquid was absorbed. While, for the equal amount of brake fluid and diesel $30 \mathrm{ml}$ of liquid was absorbed. Finally, for the composition of $0.75-\mathrm{BF}$ and $0.25-\mathrm{D}, 27 \mathrm{ml}$ of liquid was absorbed.
\end{abstract}

\section{Introduction}

Road transport is a significant branch in the developing industries that with increasing number of vehicles is the main issue for the environmental protection [1-6]. However, rising number of cars on roads is associated with higher number of car accidents which demands Fire Department engagement [7-10]. Therefore, one of the basic duties of the Fire Department in the field of the ecological protection is to support the area of car accident [11-15]. One of the severe consequences of car accidents is environmental devastation caused by leakage of petroleum substances as well as other vehicle fluids [16-18]. Therefore, substances called sorbents are considered as appropriate approach of supporting spilled liquid (sorbate) on the road [19-21]. Oil sorption materials mainly comprise inorganic mineral products, natural materials, synthetic polymers and polymer-based composites [22-25]. In the case of sudden leakages selection of the proper type of sorbent is

\footnotetext{
*Corresponding author: apolanczyk@sgsp.edu.pl
} 
mandatory, while application of the material with the best sorption properties may limit at the costs of operations [26-29]. Therefore, the aim of the study was to compare different sorbates in contact with compact sorbent and to investigate sorption properties of sorbent.

\section{Material and methods}

In this paper we focused on the analysis of sorption process concerning compact sorbent contacting with different sorbates e.g. brake fluid and diesel. Therefore, in the laboratory scale a dedicated experimental set-up was prepared (Fig.1) [11, 30, 31]. The set-up was composed of the following elements: transparent, plastic container localized below an electronic weight positioned on the antivibration table, and above the Petrie's dish [32, 33]. Moreover, the following substances were analyzed: one sorbent (compact sorbent) and two sorbates (brake fluid and diesel) [34-37]. Each time $50 \mathrm{~cm} 3$ of sorbent was contacted with $100 \mathrm{~cm} 3$ of sorbate in different proportions such as $100 \%$ of brake fluid, $100 \%$ of diesel, $75 \%$ of brake fluid and $25 \%$ of diesel, $50 \%$ of brake fluid and $50 \%$ of diesel, $25 \%$ of brake fluid and $75 \%$ of diesel [38-41].

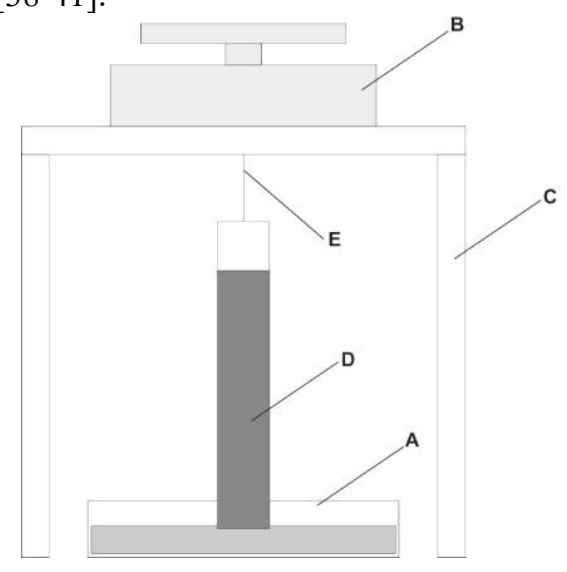

Fig. 1. A dedicated experimental set-up for sorption process analysis in laboratory scale was composed of: A - a Petri dish; B - an electronic weight; C - an anti-vibration table; D - a cylindrical container for analyzed sorbent; $\mathrm{E}-\mathrm{a}$ telescope.

Weight of sorbate was monitored every 10 seconds until electronic weight displayed three times the same value [42-45]. Moreover, each sorbate or sorbate mixture was analyzed in triplicates [45-47]. Finally, mathematical description of sorption process was showed with a non-linear regression. Following parameters were analyzed: R square and standard deviations [48-53].

\section{Results}

This paper investigates sorption process for five different cases in the laboratory scale. First, two pure sorbates (100\% brake fluid and $100 \%$ diesel) were contacted with compact sorbent (Fig.2a). The results of sorption process were presented as an amount of sorbate in function in time. It was observed that the sorption process for pure brake fluid $(100 \%)$ contacted with compact sorbent was stopped after absorption of $24.80 \pm 0.27 \mathrm{~g}$ brake fluid in time equal to $8900 \mathrm{~s}$ (Fig.2a). While, for pure diesel (100\%) contacted with compact sorbent sorption process was stopped after absorption of $21.09 \pm 0.35 \mathrm{~g}$ in time equal to 3180 s (Fig.2a). Average sorption was equal to 0.83 and 0.72 for brake fluid and diesel, respectively. Next, brake fluid and diesel were mixed in different compositions. At first 
overload of one of component in a mixture was analyzed. Therefore, following compositions of sorbates were analyzed: brake fluid $(75 \%)$ - diesel $(25 \%)$ and brake fluid $(25 \%)$ - diesel (75\%) (Fig.2b). It was observed that the sorption process for brake fluid (75\%) and diesel $(25 \%)$ contacted with compact sorbent was stopped after absorption of $18.39 \pm 0.17 \mathrm{~g}$ brake fluid in time equal to $5810 \mathrm{~s}$ (Fig.2b). Meanwhile, for brake fluid (25\%) and diesel (75\%) contacted with compact sorbent sorption process was stopped after absorption of $22.06 \pm 0.54 \mathrm{~g}$ in time equal to $3590 \mathrm{~s}$ (Fig.2b). Average sorption was equal to 0.63 and 0.37 for brake fluid (75\%) and diesel (25\%), brake fluid $(25 \%)$ and diesel $(75 \%)$, respectively. Finally, brake fluid and diesel were mixed in the same proportions (brake fluid $(50 \%)$ - diesel $(50 \%))$. It was observed that the sorption process was stopped after absorption of $21.85 \pm 0.49 \mathrm{~g}$ brake fluid in time equal to $3640 \mathrm{~s}$ (Fig.2b), with average sorption was equal to 0.72 .
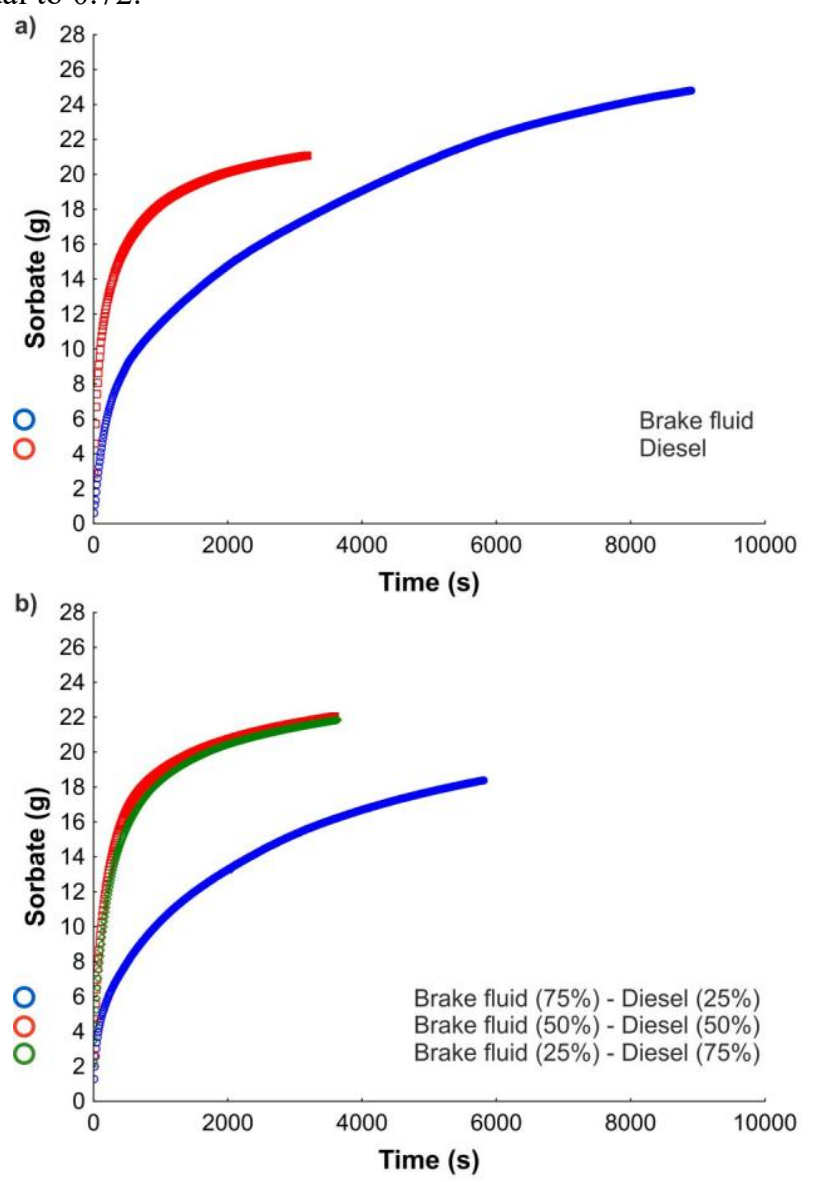

Fig. 2. Experimental results of sorption process for two sorbates in contact with compact sorbent: a) brake fluid (100\%), b) diesel (100\%). 

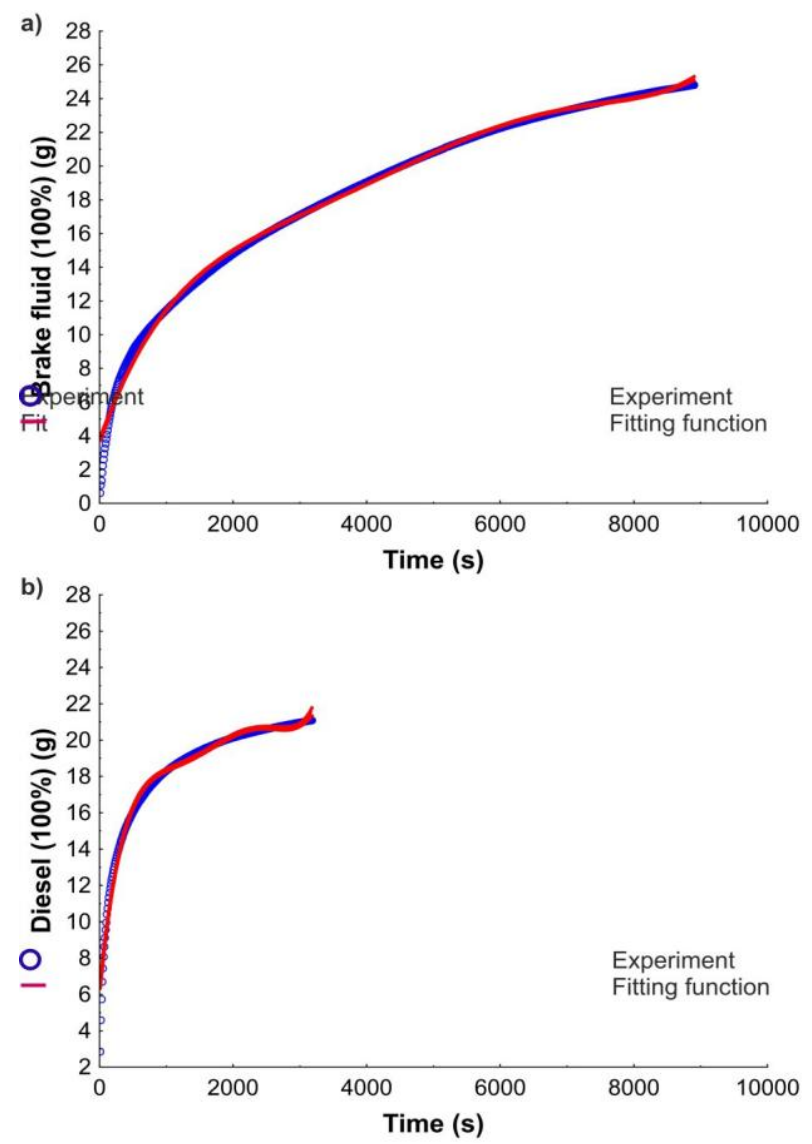

Fig. 3. Experimental results of sorption process described with mathematical function (Table 1): a) brake fluid (100\%), b) diesel (100\%).

Moreover, mathematical description of sorption process with the use of fifth degree polynomial function was applied (Table 1). It was observed that for the brake fluid in pure solution $(100 \%)$ as well as in mixture (brake fluid $75 \%$ and diesel $25 \%$ ) correlation coefficient was in range $0.92-0.95$. Furthermore, when the amount of diesel was equal to brake fluid $(50 \%)$ or higher $(75 \%)$ as well as for the pure solution $(100 \%)$ correlation coefficient was in range $0.81-0.83$.

Table 1. Non-linear description of analyzed sorbates for different process conditions. Fit - fitting function, $\mathrm{R}$ - correlation coefficient. $\mathrm{BF}$ - brake fluid; diesel D - diesel; C - compact.

\begin{tabular}{|c|c|c|}
\hline Sorbates & Fitting function & $\mathbf{R}[-]$ \\
\hline BF (100\%) & $\begin{array}{c}f(x)=2.0997+0.0175 x-1.8946 \cdot 10^{-5} x^{2}+1.1207 \cdot 10^{-8} x^{3} \\
-3.1893 \cdot 10^{-12} x^{4}+3.4383 \cdot 10^{-16} x^{5}\end{array}$ & 0.92 \\
\hline D (100\%) & $\begin{array}{c}f(x)=6.1278+0.0369 x-4.5302 \cdot 10^{-5} x^{2}+2.7727 \cdot 10^{-8} x^{3} \\
-8.0286 \cdot 10^{-12} x^{4}+8.7782 \cdot 10^{-16} x^{5}\end{array}$ & 0.83 \\
\hline $\begin{array}{l}\text { BF (75\%)/D } \\
\quad(25 \%)\end{array}$ & $\begin{array}{c}f(x)=3.3733+0.0115 x-6.0449 \cdot 10^{-6} x^{2}+1.9221 \cdot 10^{-9} x^{3} \\
-3.0208 \cdot 10^{-13} x^{4}+1.8101 \cdot 10^{-17} x^{5}\end{array}$ & 0.95 \\
\hline $\begin{array}{l}\text { BF (25\%)/D } \\
\quad(75 \%)\end{array}$ & $\begin{array}{c}f(x)=5.8357+0.038 x-4.23 \cdot 10^{-5} x^{2}+2.3053 \cdot 10^{-8} x^{3}-5.8986 \\
\cdot 10^{-12} x^{4}+5.6896 \cdot 10^{-16} x^{5}\end{array}$ & 0.81 \\
\hline $\begin{array}{l}\text { BF (50\%)/D } \\
\quad(50 \%)\end{array}$ & $\begin{array}{c}f(x)=4.7482+0.0369 x-3.9002 \cdot 10^{-5} x^{2}+2.0563 \cdot 10^{-8} x^{3} \\
-5.1451 \cdot 10^{-12} x^{4}+4.8747 \cdot 10^{-16} x^{5}\end{array}$ & 0.82 \\
\hline
\end{tabular}


Finally, graphical presentation of fitting functions for sorption process was presented on Fig.3 - Fig.5. For both pure sorbates better fitting for brake fluid compare to diesel was observed, which was manifested in a shape of fitted function. For the brake fluid fitting function was positioned almost in axis of the experimental results $(\mathrm{R}=0.92)$ (Fig.3a). While, for diesel results swirls in shape of fitting function were observed $(\mathrm{R}=0.83$ ) (Fig.3b).

Similarly, for the mixtures of analyzed sorbates was observed. Each time when higher amount of brake fluid was in a mixture, fitting function almost reflected the shape of the experimental results (Fig.4a). On the other hand for the mixtures where diesel was main component (Fig.4a) or amount of diesel was equal to brake fluid swirls in shape of fitting function were observed (Fig.5).
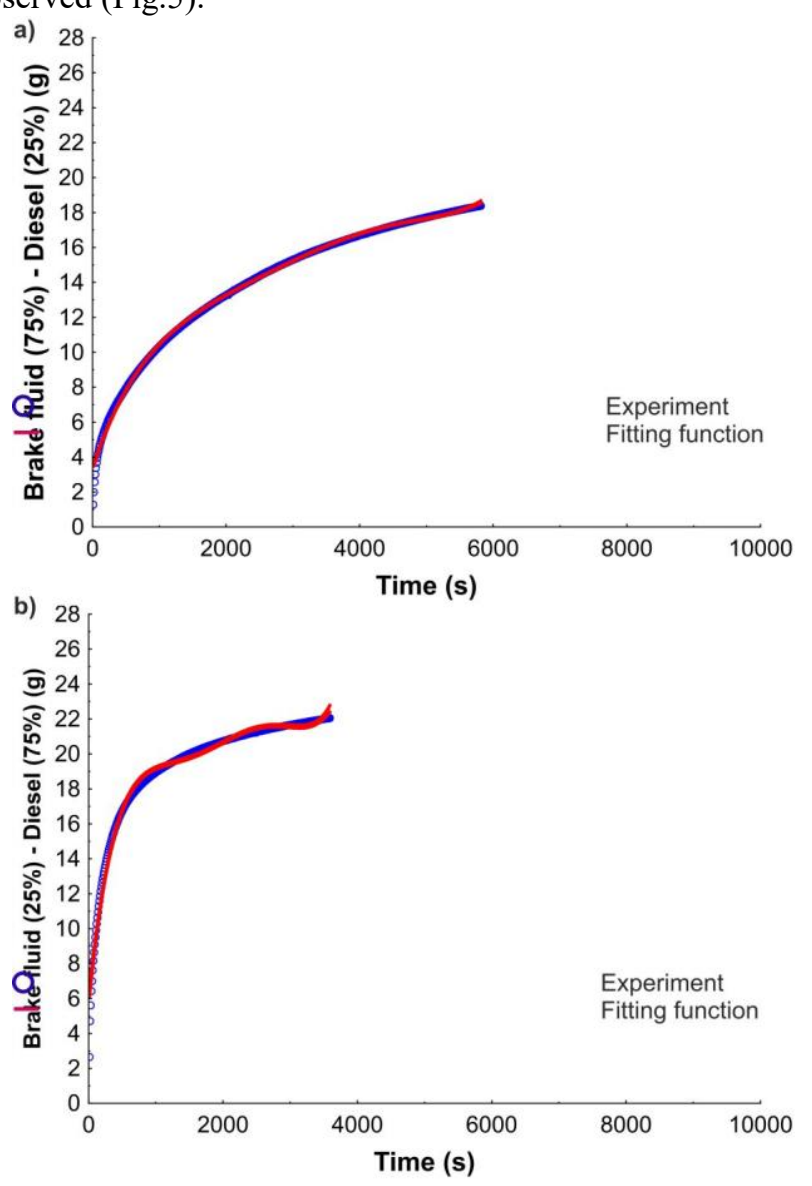

Fig. 4. Experimental results of sorption process described with mathematical function (Table 1): a) brake fluid (75\%) - diesel (25\%), b) brake fluid (25\%) - diesel (75\%). 


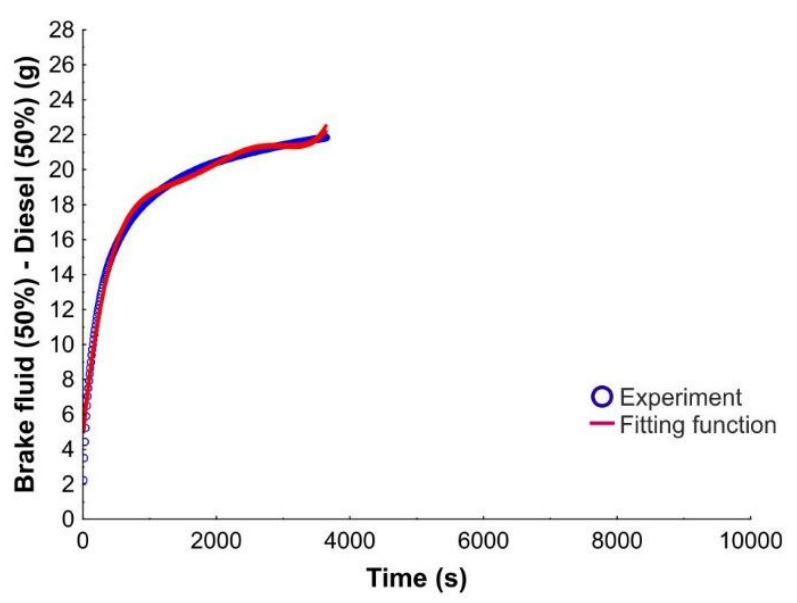

Fig. 5. Experimental results of sorption process described with mathematical function (Table 1): brake fluid $(50 \%)$ - diesel $(50 \%)$.

Moreover, it was observed that the time of sorption process decreased with higher amount of diesel. For pure diesel sorption process lasted approximately $3180 \mathrm{~s}$, while for the mixture (brake fluid $25 \%$ and diesel $25 \%$ ) it was approximately $5810 \mathrm{~s}$. In contrast sorption process for pure brake fluid was the longest and lasted approximately $8900 \mathrm{~s}$.

\section{Conclusions}

It was observed that the sorption process was extended for brake fluid compare to diesel. Decrease of brake fluid amount in the mixture resulted in a decrease of sorption value. Furthermore, increase of diesel amount in the mixture resulted in a decrease of sorption time. Moreover, higher amount of brake fluid corelated with higher value of correlation coefficients after application of fifth degree polynomial scale.

\section{References}

1. A. Polanczyk, Z. Salamonowicz, E3S Web of Conferences, 44, 8 (2018)

2. A. Polanczyk, M. Podgorski, T. Wozniak, L. Stefanczyk, M Strzelecki, Medicina 54, 15 (2018)

3. A. Polanczyk, M. Podgorski, M. Polanczyk, N. Veshkina, I. Zbicinski, L. Stefanczyk, C. Neumayer, Interact. Cardiovasc. Thora.c Surg. (2018)

4. A. Piechota-Polanczyk, M. Wlodarczyk, A. Sobolewska-Wlodarczyk, M. Jonakowski, A. Pilarczyk, K. Stec-Michalska, M. Wisniewska-Jarosinska, J. Fichna, Dig. Dis. Sci. 62 (2017)

5. A. Piechota-Polanczyk, M. Zielinska, D. Piekielny, J. Fichna, Biomed. Pharmacother. 84 (2016)

6. D. Dmochowski, A. Dmochowska, S. Biedugnis, ROS 17 (2015)

7. M. Pijarowski and W. Tic, Civil. Env. Eng. Rep. 12, 12 (2017)

8. A. Polanczyk, M. Klinger, J. Nonobachvili, I. Huk, C. Neumayer, Appl. Sci. 8, 12 (2018) 
9. A. Polanczyk, A. Piechota-Polanczyk, C. Domenig, J. Nanobachvili, I. Huk, C. Neumayer, Appl. Sci. 8, 14 (2018)

10. M. Salaga, U. Lewandowska, D. Sosnowska, P.K. Zakrzewski, A.I. Cygankiewicz, A. Piechota-Polanczyk, M. Sobczak, P. Mosinska, C. Chen, W.M. Krajewska, J. Fichna, Naunyn. Schmiedebergs Arch. Pharmacol. 387 (2014)

11. B. Petrovsky and E. Monnet, Vet. Surg. 47 (2018)

12. A. Polanczyk, M. Strzelecki, T. Wozniak, W. Szubert, L. Stefanczyk, Found. Com. Dec. Sci. 42, 13 (2017)

13. D. Dmochowski, A. Dmochowska, S. Biedugnis, ROS 17 (2015)

14. M. Tytla, A. Dmochowska and D. Dmochowski, E3S Web of Conferences 44, (2018)

15. G. Hayase, K. Kanamori, M. Fukuchi, H. Kaji and K. Nakanishi, Ang. Chem. Inter. 52, 4 (2013)

16. A. Polanczyk, A. Piechota-Polanczyk, L. Stefanczyk, PLoS One 12 (2017)

17. A. Polanczyk, M. Podyma, L. Trebinski, J. Chrzastek, I. Zbicinski, L. Stefanczyk, PLoS One 11 (2016)

18. D.D. Nguyen, N.-H. Tai, S.-B. Lee and W.-S. Kuo, Energ. Environ. Sci. 5, 5 (2012)

19. A. Polanczy, T. Wozniak, M. Strzelecki, W. Szubert, L. Stefanczyk, Signal Processing SPA 5 (2016)

20. A. Zieminska-Stolarska, A. Polanczyk, I. Zbicinski, J. Hydrol. Hydromech. 644, 8 (2015)

21. H. Bi, X. Xie, K. Yin, Y. Zhou, S. Wan, L. He, F. Xu, F. Banhart, L. Sun and R. Ruoff, Advanc. Function. Mat. 22, 5 (2012)

22. A. Polanczyk, M. Podyma, L. Stefanczyk, W. Szubert, I. Zbicinski, J. Biomech. 48 (2015)

23. W. Eilenberg, S. Stojkovic, A. Piechota-Polanczyk, C. Kaun, S. Rauscher, M. Groger, M. Klinger, J. Wojta, C. Neumayer, I. Huk, S. Demyanets, Eur. J. Vasc. Endovasc. Surg. 51 (2016)

24. H. Zatorski, M. Salaga, M. Zielinska, A. Piechota-Polanczyk, K. Owczarek, R. Kordek, U. Lewandowska, C. Chen, J. Fichna, Naunyn. Schmiedebergs Arch. Pharmacol. 388 (2015)

25. Eakalak Khan, Wanpen Virojnagud and Thunyalux Ratpukdi, Chemosphere 57, 9 (2004)

26. A. Polanczyk, P. Wawrzyniak, I. Zbicinski, Drying Technol. 31, 10 (2013)

27. P. Wawrzyniak, A. Polanczyk, I. Zbicinski, M. Jaskulski, M. Podyma, J. Rabaeva, Drying Technol. 30, 10 (2012)

28. A. Piechota, A. Goraca, J. Physiol. Pharmacol. 62 (2011)

29. Z. Salamonowicz, M. Kotowski, M. Polka, W. Barnat, Bull. Pol. Ac.: Tech. 63 (2015)

30. W. Jarosz, Z. Salamonowicz, M. Majder-Lopatka, R. Matuszkiewicz, A. Dmochowska, Przem. Chem. 93 (2014)

31. Z. Salamonowicz, M. Kotowski, M. Polka, W. Barnat, Przem. Chem. 93 (2014)

32. Z. Salamonowicz, M. Wolinski, M. Sobolewski, M. Polka, Przem. Chem. 93 (2014)

33. M. Polka, Z. Salamonowicz, M. Wolinski, B. Kukfisz, Procedia Eng. 45 (2012)

34. M. Wlodarczyk, A. Sobolewska-Wlodarczyk, A.I. Cygankiewicz, D. Jacenik, A. Piechota-Polanczyk, K. Stec-Michalska, W.M. Krajewska, J. Fichna, M. WisniewskaJarosinska, J. Gastrointestin. Liver Dis. 26 (2017) 
35. M. Salaga, L.V. Blomster, A. Piechota-Polanczyk, M. Zielinska, D. Jacenik, A.I. Cygankiewicz, W.M. Krajewska, J.D. Mikkelsen, J. Fichna, J. Pharmacol. Exp. Ther. 356 (2016)

36. A. Piechota-Polanczyk, S. Demyanets, O. Nykonenko, I. Huk, M. Mittlboeck, C.M. Domenig, C. Neumayer, J. Wojta, J. Nanobachvili, M. Klinger, Eur. J. Vasc. Endovasc. Surg. 45 (2013)

37. A. Polanczyk, M. Podyma, L. Stefanczyk, I. Zbicinski, Chem. Eng. Process. 33, 9 (2012)

38. T. Wesierski, M. Majder-Lopatka, W. Wasik, Przem. Chem. 96, 5 (2017)

39. A. Piechota-Polanczyk, A. Goraca, Pharmacol. Rep. 64 (2012)

40. A. Piechota, A. Polanczyk, A. Goraca, Pharmacol. Rep. 63 (2011)

41. T. Wesierski, M. Majder-Lopatka, R. Matuszkiewicz, R. Porowski, Przem. Chem. 91, 3 (2012)

42. M. Majder-Lopatka, W. Rogula-Kozlowska, W. Wasik, E3S Web of Conferences 44 (2018)

43. A. Piechota, A. Polanczyk, A. Goraca, Pharmacol. Rep. 62 (2010)

44. M. Majder-Lopatka and T. Wesierski, E3S Web of Conferences 46 (2018)

45. M. Majder-Lopatka, T. Wesierski, W. Wasik, BITP 42, 8 (2016)

46. A. Piechota-Polanczyk, A. Jozkowicz, Curr. Drug Targets. 17 (2016)

47. Z. Salamonowicz, R. Makowski, E3S Web of Conferences 44 (2018)

48. P. Wawrzyniak, M. Podyma, I. Zbicinski, Z. Bartczak, A. Polanczyk, J. Rabaeva, Drying Technol. 30, 9 (2012)

49. Z. Salamonowicz, W. Jarosz, BITP 3 (2012)

50. A. Piechota-Polanczyk, A. Kopacz, D. Kloska, B. Zagrapan, C. Neumayer, A. Grochot-Przeczek, I. Huk, C. Brostjan, J. Dulak and A. Jozkowicz, Oxid. Med. Cell. Longev. 2018 (2018)

51. K. Kowalska, D.E. Habrowska-Gorczynska, C. Neumayer, M. Bolliger, C. Domenig, A. W. Piastowska-Ciesielska, I. Huk and A. Piechota-Polanczyk, Acta Biochim. Pol. 65, 1 (2018)

52. D. Kloska, A. Kopacz, A. Piechota-Polanczyk, W. Nowak, J. Dulak, A. Jozkowicz and A. Grochot-Przeczek, Vascul. Pharmacol. (2018) [in press]

53. Z. Salamonowicz, M. Majder-Lopatka, BITP 30 (2013) 